\title{
RESEARCH ON THE PROPERTIES OF Co-TiC AND Ni-TiC HIP-SINTERED ALLOYS
}

\author{
Tetiana CHEREPOVA, ${ }^{* *}$ Galyna DMITRIEVA, ${ }^{* *}$ Oleksandr TISOV, ${ }^{*}$ Oleksandr DUKHOTA, ${ }^{*}$ Myroslav KINDRACHUK
}

*Engineering Department, Aerospace Institute, National Aviation University, 1 Kosmonavta Komarova Ave., UA-03058, Kyiv, Ukraine ${ }^{*}$ G.V. Kurdyumov Institute for Metal Physics, of N.A.S. of Ukraine, 36 Academician Vernadsky Boulevard, UA-03142 Kyiv, Ukraine

cherepova_ts@meta.ua, dmytrievaGP@nas.gov.ua, tisov@nau.edu.ua, zlpat@nau.edu.ua, nau12@ukr.net

received 13 April 2018, revised 22 March 2019, accepted 27 March 2019

\begin{abstract}
Three types of sintered alloys were fabricated based on cobalt, nickel and high-temperature alloy ZhS32-VI matrix with titanium carbide strengthening phase. TiC content was in a range of 30-50 vol. \%. The melting temperatures of alloys are higher than $1320^{\circ} \mathrm{C}$, and they may undergo undamaged through all technological procedures together with turbine blades, including soldering and outgassing. DSC analyses indicates no additional thermal effects until melting, which confirms their structural stability. The examinations of microstructure revealed three types of constituents - TiC particles, matrix solid solution and blow outs - structural defects having negative effects on all the studied properties. It was found that heat resistance of nickel based sintered alloys at the temperature of $1100^{\circ} \mathrm{C}$ is superior as compared with the alloys based on cobalt and alloy ZhS32-VI. It has been established that wear resistance in conditions of fretting wear at temperatures of $20,850,950$ and $1050^{\circ} \mathrm{C}$ of sintered alloy with $\mathrm{ZhS} 32-\mathrm{VI}$ matrix is mostly superior as compared with the other alloys. The properties of produced alloys allow to use them for manufacturing of components of friction couples operating in conditions of high temperature fretting wear, including protective pads of turbine blades top shrouds contact faces.
\end{abstract}

Key words: Cobalt, nickel, titanium carbide, sintered alloys, heat resistance, wear resistance, melting temperature

\section{INTRODUCTION}

The problems of improving power, reliability and durability are the particular focus areas of designing, operation and repair of aircraft gas turbine engines. Their long service life is strongly related to wear resistance of the contact surfaces of turbine rotor blades. They are continuously affected by high temperature, heavy loads, high rates of heating and cooling and corrosioninducing products of fuel combustion. After prolonged use, turbine blades are usually worn out at the contacting surface of blade shrouds. The effective method to improve their wear resistance is deposition of a wear resistant material to the surface of blade shroud (Tretiachenko et al, 1975).

New generation engines should have increased power, weight-to-power efficiency and reduced fuel consumption. This is achieved through technological methods, and particularly by increasing the fuel combustion temperature. In turn, all this leads to increased loading (mechanical and thermal) of gas turbine engine (GTE) components, reducing their service life. To overcome the arising problems, new materials should be produced. Their key properties are heat resistance, mechanical (compression and shear) strength and fretting resistance. They should comply with a set of requirements of engine manufacturers (Leontiev et al, 2006).

As of today, one of the methods used for Motor Sich engines is the use of cast eutectic alloys as a material for various cladding processes. They are applied to the shroud friction surface. Namely, the cobalt based alloys XTH-61 and XTH-62 (Dmytrieva et al, 2015, Cherepova et al, 2014) are the most widely used.

These alloys are strengthened by $\mathrm{NbC}$ particles. Coarser particles - proeutectic crystals, fine particles - a product of eutectic transition. The cobalt matrix is reinforced by macro and micro carbide particles simultaneously, providing a combined strengthening mechanism. Wear resistance of this type of natural composites is dependent on matrix mechanical strength, type of reinforcement and components ratio. Generally, increasing of carbide amount promotes improvement of wear resistance. However, the higher amount of carbides produces higher stresses in matrix material. In conditions of high temperature, this may cause matrix material softening, and then, sintered alloy will not be able to perform its task.

The matrix of these alloys has acceptable heat resistance, but not high enough carbides content. Unfortunately, the amount of carbides in cast alloy is limited: increasing leads to coarsening of carbide grain and embrittlement. Further improvement of wear resistance is possible by methods of powder metallurgy. It allows precise control of both amount and size of carbides. As a matrix material, authors decided to use cobalt and nickel based heat resistant alloys (nickel and cobalt alloyed with chromium, iron and aluminium), and one more alloy - complex high-temperature alloy $\mathrm{ZhS} 32-\mathrm{Vl}$. As a strengthening phase, titanium carbide was selected. Produced sintered alloys (HIP) have superior wear resistance if compared with the above mentioned cast alloys. In addition, the ratio of the components and the size of the carbides may be varied in the broad range of values. Levashov et al. (2003) conducted a good research on the properties of Nickel alloy KhN7OYu+TiC sintered material. In this research, the matrix material was alloyed with chromium, aluminium and iron, but in lesser amounts compared to our experimental Ni-matrix. At the same time, KhN7OYu+TiC sintered material was strengthened with $y^{\prime}$ precipitates, as in alloy ZhS32-VI. Also, they reported considerable effect of nanomodification by $\mathrm{ZrO}_{2}, \mathrm{Al}_{2} \mathrm{O}_{3}$, W, WC, WC-Co, $\mathrm{NbC}$, and $\mathrm{Si}_{3} \mathrm{~N}_{4}$ on the structure and mechanical properties of the 
sintered material. Shuster et al. (2016) studied the tribological properties of TiC+ ZhS6U (nickel based alloy) cermet in dry sliding (ball-on-disk) at room temperature. They reported good wear resistance of the material, especially if it is additionally coated with $\mathrm{TiC}$ or TiN layer, preventing outcropping of TiC particles from the test piece. Unfortunately, no high-temperature tests were made.

TiC-particles are widely used for the strengthening of structural materials. This may be both bulk and surface strengthening. One of the methods is laser melting of preplaced powder material on the surface of AISI 304 steel part (Chinmaya and Manoj, 2015). TiC with 10-14 $\mu \mathrm{m}$ grain size was used. Laser provides good bonding of preplaced material components and adhesion of the coating to substrate. Cladding of TiC-Co composite coating on the surface of $2 \mathrm{Cr} 13$ steel was done by Wei, 2012. He used the coating to increase the useful life of various engineering products, including moulds and turbine blades. Coating had a complex structure with several layers distinguished. The substrate was self-hardened, followed by bonding and transition zones. The cladding layer consisted of oversaturated cobalt dendrites with dispersed TiC particles. For steels, additional strengthening effect provided by self-hardening (depending on steel grade) may be achieved. But, in case of superalloys, this will change the composition and structure of the surface layer (as a result of interdiffusion and melt mixing), but this is not very much expected.

Steel $316 \mathrm{~L}$ is also a very popular material as a matrix for TiC reinforced MMC's. Chukwuma et al., 2016. Production technique - melt infiltration. TiC contend was 70-90 vol. \%, grain size 4-10 $\mu \mathrm{m}$. Sliding wear tests indicated a trade-off between TiC grain size and matrix-to-filler ratio. Coarser grain size promoted higher specific wear rate, increasing the binder content increased wear rate. Also, the formation of tribolayer with high $O$ content was revealed. The predominant wear mechanism on the initial stage - two-body abrasive wear, being followed by three-body abrasive wear. But, at higher temperatures (which was not studied in the considered research), a tribo-chemical friction-induced layer will be formed in the early period of friction, and may protect the material from carbides spallation and abrasive action of nonoxidized TiC grain fragments. Sakamoto et al., 2015 used 2 wt. \% TiC nanoparticles to significantly enhance the mechanical properties of $316 \mathrm{~L}$ austenitic stainless steel.

TiC-Co composites were studied by Sun-A Jung et al., 2015. The specimens were prepared by using the combination of high energy milling followed by liquid phase sintering. The TiC grain size was 7-10 $\mu \mathrm{m}$. The importance of grain of TiC and matrix material were highlighted. Namely, fine powders of Co inhibit the TiC grain growth during sintering. Unfortunately, the authors did not do any tribological examinations. Karantzalis et al., 2013, fabricated the $\mathrm{Co}$ and Co-based composites reinforced by $\mathrm{TiC}$ particles. They used the method of vacuum arc melting to fuse the alloy constituents. Larger amount of TiC promoted coarsening of its grains. The sliding wear test gave promising results.

Another Co-TiC sintered alloy was studied by Jung et al. (2015). Modification of powder starting material with nanosized Co powder allowed to decrease the sintering temperature. Obtained alloy has good thermal stability and mechanical properties, and is reported to be harder than analogical Ni-based alloy, which is in good agreement with the current paper.

Anasori et al., 2014, 2016 reported an excellent damping capacity of Mg-alloys bonded carbides. They studied the energy absorption of alloys with 5,20 and $50 \%$ (vol.) of $\mathrm{TiC}$ and $\mathrm{Ti}_{2} \mathrm{AlC}$. The favourable size of particulate reinforcements is $5-15 \mu \mathrm{m}$. The effect of damping is achieved by inherent damping capacity of materials, area of matrix-carbide interface, dissimilarity of heat expansion coefficient. This increases the amount of dislocations. So, we believe that 'crashed' carbide particles will provide better energy absorption compared to 'as cast' carbides, and better relief for friction-induced stresses.

Zhang at el, 2000, studied the microstructure and mechanical properties of combustion synthesized and hot compacted gradient TiC-Ni coatings. Ni content wary from 10 to $50 \mathrm{wt}$. \%. The average size of TiC grain was (according to the microstructures published) $1-10 \mu \mathrm{m}$ and is dependent on nickel content (more nickel - finer $\mathrm{TiC}$ grain). Maximum mechanical properties are observed when $\mathrm{Ni}$ content is $20-30$ wt. \%.

Bin et al., 2013 studied the microstructure and tribological behaviour of $\mathrm{TiC}$ reinforced nickel-based alloy. They report about decreasing trend of friction coefficient when the content of TiC particles rises up to $30 \%$. At the same time, the wear rate reduces by a value of one third. Further increase of TiC content worsens the tribological behaviour of the composite. They also report about a critical load of about 10-12 MPa when the transition from slight adhesion wear to severe abrasive wear as a result of desquamation of hard tribolayer and material constituents.

Bin et al., 2013, also found that TiC particles reduce friction coefficient and wear losses of Ni-based alloy. The main wear mechanism is micro-cutting. The increase in temperature up to $300^{\circ} \mathrm{C}$ intensifies the adhesion interaction and increases the wear loss from 4 to $7 \mathrm{mg}$. This is not very understandable because $15 \% \mathrm{Cr}$ alloyed Ni usually has better or at least similar wear resistance if compared with the room temperature test results. The reason of this, as we think, is in the use of 7005 aluminium alloy as a substrate for TiC-Ni plasma spray coating. It's load carrying capacity at $300^{\circ} \mathrm{C}$ is reduced. Yuxin et al., 2009, used direct laser fabrication technique to fabricate 20 to $60 \mathrm{vol}$. \% TiC reinforced Ni-based material. They highlight enhanced wear resistance as the TiC content rises.

Shokat et al., 2015, studied the spark plasma sintering method fabricated in situ Ni-TiC coating. The resultant coating had a structure of $\mathrm{Ni}$ matrix strengthened by about 40 vol. \% of TiC nanoparticles. Authors, unfortunately, did not study the mechanical properties of the obtained coating, except hardness. Wear tests also were not conducted.

$\mathrm{TiC}$ is also used to strengthen aluminium-based alloys. Baskaran et al., 2015 studied the friction behaviour of high strength heat treatable aluminium alloy 7075 with the addition of 4 or $8 \%$ of TiC to the material. Unfortunately, the authors omitted the temper state of the alloy being examined. So, the strengthening of precipitation-hardened alloys by TiC is also being done.

Taoyuan Ouyang et al., 2016, highlight the property of TiC particles to release $\mathrm{TiO}_{2}$ oxide playing role of healing agent. This is observed only at high temperatures, and the preoxidation of the surface may be used demonstrating about $29 \%$ better oxidation resistance. Thus, MMC's containing TiC particles may have selfhealing effect at high temperature friction and fretting interaction.

Having summarized the above material, the following figureouts have been made:

- TiC is a very promising material to be used as strengthening phase in the production of MMC's for various friction applications. They have good wear resistance in dry sliding friction. As matrix material, many metals and alloys are used, including cobalt, nickel, magnesium, aluminium alloys and steels.

- Most scientists did the wear assessments of Me-TiC composites at room temperatures in conditions of dry sliding friction. 
The results of fretting-wear tests are hardly available in the opened literature. The same refers to the high temperature fretting testing of these materials. The heat resistance and high temperature oxidation behaviour of the mentioned composites is also not highlighted.

- Most of the authors have produced composites by sintering techniques. The volume fraction of carbides is $40-60 \%$ for most studies. Microstructural examinations indicate good mixing and uniform distribution of alloying elements and carbide particles in matrix material.

- Depending on the type of material and test conditions, increasing of $\mathrm{TiC}$ content to high values may have both beneficial (Chukwuma et al., 2016) or adverse effect (Bin et al., 2013). But, it should be mentioned that reinforcing metal matrix by TiC has a desired effect on friction behaviour at an individual level for each system matrix-to-filler ratios.

For the current research, we decided to cover the following issues:

- to produce MMC's based on nickel and cobalt alloyed matrices having the same alloying system; precipitationstrengthened alloys may also be modified by TiC particles, and for our research we used nickel-based alloy ZhS32-VI

- to study the properties of fabricated alloys by doing microstructure examinations of alloys and assessments of their wear resistance in conditions of high temperature fretting (up to $1050^{\circ} \mathrm{C}$ ); studying their thermodynamic stability and high temperature oxidation behaviour

- to assess the possibility of using these materials for the protection of GTE turbine blades as bonded plates to the surface of top shroud contact face

Current work presents the results of examinations of basic properties of sintered alloys with heat resistant matrix and titanium carbide as a strengthening phase; basically: melting point, heat resistance at maximum possible temperature and wear resistance in conditions of high temperature fretting wear. The main objective of the article is to make a presentation of these materials as future aerospace materials.

\section{MATERIALS AND METHODOLOGY OF RESEARCH}

The objects of the work are three types of alloys. First, sintered alloys using powders of cobalt, titanium carbide and alloying elements - chromium, iron and nickel. Second, the same components, except cobalt substituted with nickel. As a matrix material for the third type of alloys, a high-temperature precipitation hardening nickel-based alloy ZhS32-VI was used, the filler is the same as for the other two alloys - titanium carbide. The specimens of the alloys were produced by HIP method with SPD-120 equipment, utilizing graphite moulds and induction heating. The air was replaced by $\mathrm{CO}$ to avoid the oxidation of unwanted components. The particle size of used powders was 5-20 $\mu \mathrm{m}$ : cobalt powder PK-1U (total impurities up to $0.65 \%$ ), nickel powder of PNE-1 grade $(99.9 \%$ of Ni content), chromium PACh-99H5, iron PIV1, aluminium PA-0 and alloy ZhS32-VI (OST 1.90.126-85). Chemical composition of the materials for matrix alloy production is given in Tab. 1. Titanium carbide TiC (according to standard TU 06173-74) with particle size 5-10 $\mu \mathrm{m}$ was used as the strengthening phase of metal matrix composites being studied.

For alloys of $1^{\text {st }}$ and $2^{\text {nd }}$ type, in order to get the required level of heat resistance, alloying elements (solved in nickel or cobalt) were selected analogically to an alloy XTN-62, except tungsten.
The solid solution strengthening effect of tungsten was balanced by adding sufficient amount of $\mathrm{TiC}$. To consume the undesired carbon in TiC grains (about 1.5\%) and to avoid formation of other carbides, a precisely measured amount of titanium hydrate was used.

Components of the alloys were mixed with alcohol in planetary ball mill for 2 hours, and after this, the prepared mixture was dried. Premixed components then were placed in a die mould with initial pressure $20 \mathrm{kN}$ applied. Then, the die mould was placed into an induction heater and was heated up to $1000^{\circ} \mathrm{C}$. This pretreatment allows to burn oxygen and to get $\mathrm{CO}$ (carbon monoxide) protective atmosphere during burning of graphite. The rate of temperature rise was $50^{\circ} \mathrm{C} / \mathrm{min}$. The temperature was measured by optical pyrometer 'Promin' with accuracy $\pm 20^{\circ} \mathrm{C}$. The best results of compaction were obtained when the temperature $T$ was in the range of $1320-1450^{\circ} \mathrm{C}$ and the pressure $\mathrm{P}-10 \mathrm{MPa}$. The powders were under load until the end of shrinkage, which was controlled by the dial indicator with and accuracy of $10 \mu \mathrm{m}$. Specimens for tribological tests were cut by electro-erosive method.

The density of alloys being investigated was measured using the Archimedes immersion technique. We were focused on achieving the minimum value of porosity.

Temperature of phase transformations - beginning and the end of melting, beginning and the end of solidification, solid state transformations were determined by the method of differential scanning calorimetry (DSC) with 'Netzsch DSC 404 F1 Pegasus' instrument. The other method is differential thermoanalyses (DTA) with high temperature differential thermoanalyzer VDTA-8M (specimens were heated at the rate of $50-80^{\circ} \mathrm{C} / \mathrm{min}$. in helium atmosphere).

Microstructural examinations were carried out using the light microscope OLYMPUS IX70 at magnifications of $\times 50-500$ and by scanning electron microscopy (JSM-6400 [JEOL Ltd]), additionally equipped with energy dispersion system.

$\mathrm{XRD}$ profiles of the specimens after heat resistance test were done using JEOL JSM6360LA SEM equipped with EDS.

Heat resistance of alloys being investigated was determined by weight gain per unit area. For testing, the specimens were placed into induction furnace in individual $\mathrm{Al}_{2} \mathrm{O}_{3}$ crucible. The heating up to $\mathrm{T}=1100^{\circ} \mathrm{C}$ was carried out in the atmosphere of laboratory air. Temperature of heating was controlled by thermocouple. Annealing time intervals were 10 hours followed with furnace cooling, and the total annealing time was 50 hours. The weight increment was measured after each annealing stage.

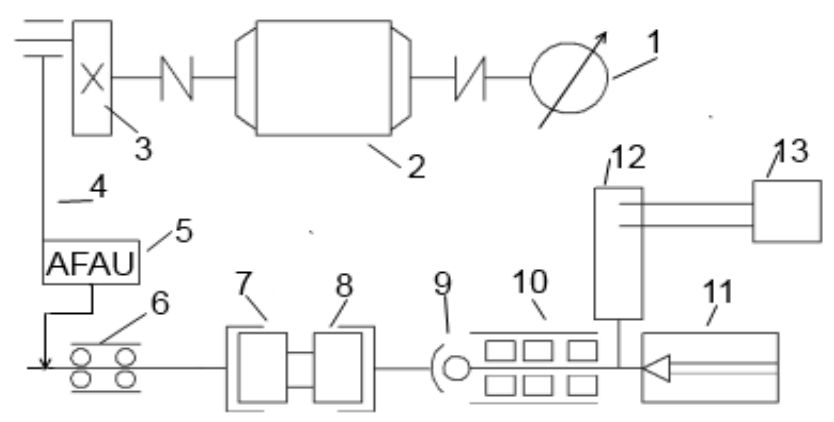

Fig. 1. The layout of wear test machine MFK-1: 1 - dial type rpm counter; 2 - electrical motor; 3 - adjustable crank-shaft unit; 4 - vertical connecting rod; 5 - amplitude fine adjustment unit; 6 - headstock; 7 - moving specimen; 8 - fixed specimen; 9 - self-aligning fixture; 10 tailstock; 11 - loading unit; 12 - strain gauge unit; 13 - data collector 
Tetiana Cherepova, Galyna Dmitrieva, Oleksandr Tisov, Oleksandr Dukhota, Myroslav Kindrachuk Research on the Properties of Co-TiC and Ni-TiC HIP-Sintered Alloys

Tab. 1. Chemical composition of metal components of powder alloys matrix

\begin{tabular}{|c|c|c|c|c|c|c|c|c|c|c|c|c|}
\hline \multirow[t]{2}{*}{ \# } & \multirow[t]{2}{*}{ Material } & \multicolumn{11}{|c|}{ Chemical element, mass fractions } \\
\hline & & $\mathrm{Fe}$ & $\mathrm{Cr}$ & Co & $\mathrm{Ni}$ & $\mathrm{Al}$ & $\mathrm{Cu}$ & $\mathrm{Mn}$ & $\mathrm{Si}$ & C & $\mathrm{S}$ & $P$ \\
\hline 1 & PK-1U & $<0.2$ & - & $\min 99.35$ & $<0.4$ & - & $<0.04$ & - & $<0.02$ & $<0.02$ & - & - \\
\hline 2 & PACh 99H5 & $<0.5$ & $\min 99$ & - & - & $<0.5$ & $<0.01$ & - & $<0.2$ & $<0.03$ & $<0.02$ & $<0.02$ \\
\hline 3 & PIV1 & Balance & - & - & - & - & $<0.02$ & $<0.1$ & $<0.08$ & - & $<0.015$ & $<0.15$ \\
\hline 4 & PA1 & $<0.35$ & - & - & - & $\min 99$ & $<0.02$ & - & $<0.4$ & - & - & - \\
\hline 5 & ZhS32-VI & W 8.2 & 5.1 & 9.3 & Balance & 5.8 & Mo 1.1 & $\mathrm{Nb} 1.6$ & Ta 4.0 & $\operatorname{Re} 4.0$ & $\operatorname{Zr} 0.05$ & B 0.015 \\
\hline 6 & PNE-1 & 0.01 & - & 0.15 & $\min .99 .8$ & - & 0.01 & - & - & 0.02 & 0.03 & - \\
\hline
\end{tabular}

The study of material wear at fretting conditions requires the simulation of contact interaction between the contiguous surfaces in the mode of tangential oscillatory displacement. In this paper, such conditions were modelled on a wear test machine MFK-1 (Dukhota and Tisov, 2010). Its layout is shown in Fig. 1.

This allowed coarse adjustment of fretting amplitude. The frequency of rotation and the number of revolutions were recorded in rpm at counter 1 . The fixed specimen 7 was fixed in a freely centred chuck, mounted on the shaft headstock 6 . The loading of the samples was carried out by the screw type loading unit 11. The axial load on the samples was recorded using a dynamometer ZIP 02-79 (GOST 2283-79) with a measuring range $0.22 \mathrm{kN}$. Registration of friction force was carried out by data collector 13 with the help of strain gauge 12 .

The amplitude of moving sample 7 oscillations was adjusted by changing the eccentricity of crank shaft 3 (coarse) and by the change in the horizontal arm length of amplitude fine adjustment unit 5. Coarse and fine adjustment allowed to change amplitude value in 10-1000 $\mu \mathrm{m}$ range, with accuracy $-2-10 \mu \mathrm{m}$. The relative displacement amplitude is defined as the difference between amplitudes of movable and fixed specimens oscillations. The amplitude was measured directly on the samples with the help of optical binocular microscope MBS-2 (with magnification 8-56) using a stroboscopic effect (stroboscope TST-100).

Linear wear was determined by profiling the ring-shaped wear track that was formed on the working surface of a fixed specimen in eight equilateral directions (Fig. 2) and was determined by the formula 1:

$$
H_{i}=\sum_{1}^{8} h_{j}
$$

where: $h_{j}$ - distance between mean lines of initial surface and wear track bottom profiles.
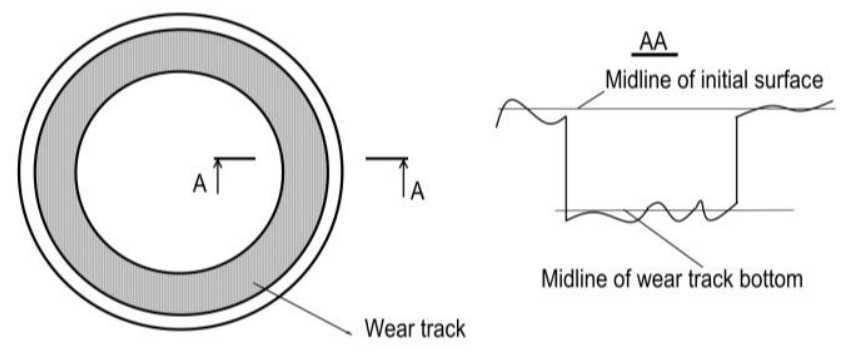

Fig. 2. Measuring linear wear

Profiling was carried out with the help of a 'Caliber'-type profilometer, which allows to measure the wear value $h_{j}$ down to 0.1 $\mathrm{mm}$ with an accuracy of $1 \times 10^{-4} \mathrm{~mm}$. Each wear track was virtual- ly divided into 8 sectors. The profilograms were made starting from the centre. To determine the linear wear, a mean value of these 8 profilograms was calculated.

\section{RESULTS AND DISCUSSION}

\subsection{Estimation of heat sensitivity of Alloys}

The melting temperature of the produced alloys is a very important issue. It should comply with the technological process of blades manufacturing, particularly soldering and outgassing procedures $\left(1270^{\circ} \mathrm{C}\right)$; so in our case, taking into account the inaccuracies and random temperature deviations, it should be not less than $1300^{\circ} \mathrm{C}$. The composition of alloys with TiC content $30,40 \mathrm{i}$ $50 \%$ (volume fractions), with cobalt, nickel and alloy ZhS32-VI matrix and their melting points are listed in Tab. 2.

Thermal heating curves of powder alloys with TiC content 30 $50 \%$, obtained by DTA and DSC confirm the possibility to fabricate composite materials based on nickel, cobalt and alloy ZhS32$\mathrm{VI}$ without any phase transitions in solid state. Earlier, the attempts to study this by DTA analysis were performed, indicating good thermal properties of Ni-TiC sintered alloys, modified by cobalt or molybdenum. The maximum peaks are in the same temperature range as in current paper (Takashi et al. [1981]). Volkova et al. (1989) also reports high stability of the system. TiC particles dissolve nickel at maximum of $0.8 \%$, and long holding time during sintering (up to 100 hours) helps to round their edges. Dissolved amounts of TiC will precipitate in nickel matrix, forming eutectic structure.

The absence of any additional thermal effects at heating is an evidence of structural and phase stability of produced composite materials. An example of the heating-cooling curves for $\mathrm{Ni}-40$ vol. $\mathrm{TiC}$ alloy are given in Fig. 3 .

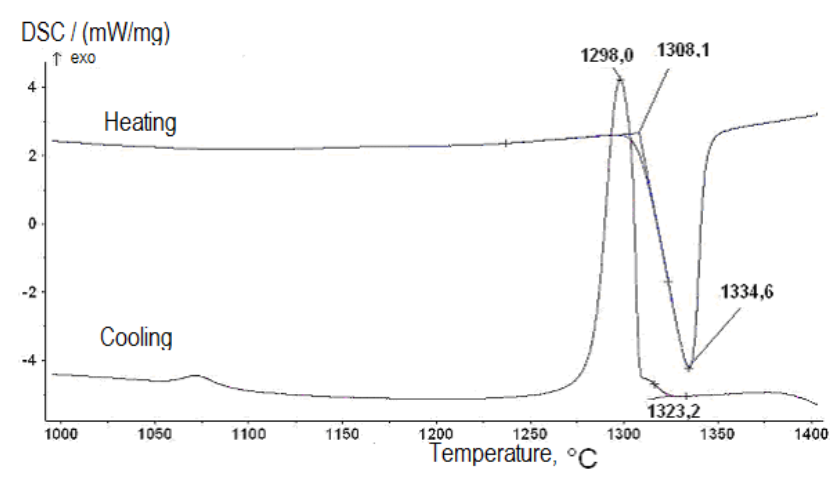

Fig. 3 The DSC curves of Ni-based alloy with 40 vol. $\%$ TiC 
At temperatures above melting point, alloys lose their phase stability. This is proved by the rising of additional thermal effects at cooling. Melting temperatures of produced alloys are of the same value: $1320-1370^{\circ} \mathrm{C}$, alloys based on ZhS32-VI are a little superior to others. The content of titanium carbide has no noticeable effect on melting temperature. Based on this, we can state that during sintering, TiC is not decomposed, and excessive carbon is effectively consumed by $\mathrm{TiH}$. The minimum temperature of melting start of alloys (solidus temperature) is not less than $1320 \pm 10^{\circ} \mathrm{C}$ and is not dependent on $\mathrm{TiC}$ content in range of $30-50$ vol. \%.

Tab. 2. Composition and melting point of composite sintered alloys

\begin{tabular}{|c|c|c|c|c|c|c|c|c|c|c|}
\hline \multirow{2}{*}{ № } & \multicolumn{3}{|c|}{ Base, mass \% } & \multicolumn{2}{|c|}{$\mathrm{TiC}$} & \multirow{2}{*}{$\begin{array}{c}\mathrm{TiH}, \\
\text { mass. } \%\end{array}$} & \multicolumn{3}{|c|}{ Alloying elements, mass \% } & \multirow{2}{*}{$\mathrm{T}_{\text {melt. }},{ }^{\circ} \mathrm{C}$} \\
\hline & Co & $\mathrm{Ni}$ & ZhS32-VI & $\%$ vol. & mass. $\%$ & & $\mathrm{Cr}$ & $\mathrm{Fe}$ & $\mathrm{Al}$ & \\
\hline 74 & 55.5 & - & - & 30 & 17.84 & 1.16 & 19.6 & 2.95 & 2.95 & 1350 \\
\hline 13 & 50.0 & - & - & 40 & 25.36 & 1.64 & 17.7 & 2.65 & 2.65 & 1320 \\
\hline 14 & 43.83 & - & - & 50 & 33.8 & 2.2 & 15.51 & 2.33 & 2.33 & 1325 \\
\hline 80 & - & 55.5 & - & 30 & 17.84 & 1.16 & 19.6 & 2.95 & 2.95 & 1330 \\
\hline 6 & - & 50.0 & - & 40 & 25.36 & 1.64 & 17.7 & 2.65 & 2.65 & 1320 \\
\hline 7 & - & 43.83 & - & 50 & 33.8 & 2.2 & 15.51 & 2.33 & 2.33 & 1320 \\
\hline 100 & - & - & 81 & 30 & 19 & - & - & - & - & 1370 \\
\hline 101 & - & - & 73 & 40 & 27 & - & - & - & - & 1355 \\
\hline 102 & - & - & 64 & 50 & 36 & - & - & - & - & 1355 \\
\hline
\end{tabular}

\subsection{Hardness values}

A very important indication of wear resistance is the hardness of alloys. We measured it using the Rockwell method. Hardness test results indicate strong impact of TiC content on hardness of alloys being investigated. Generally, increase of carbide content leads to increase of hardness. It has been found that increase of TiC content over $50 \%$ (vol.) has no beneficial effect on hardness. The hardness of cobalt based alloy having $30 \%$ (vol.) of TiC is 52 HRC. Alloys with 50 and $60 \%$ (vol.) of TiC have the same value of hardness, namely $67 \mathrm{HRC}$. The hardness of alloys with $50 \%$ (vol.) of TiC for nickel and cobalt matrix is 64 and $67 \mathrm{HRC}$, respectively.

\subsection{Redistribution of elements beneath the oxide film}

Wear and fretting resistance are structure sensitive properties. The matrix-filler ratio is one of decisive factors of wear resistance. The microstructural examinations indicate a uniform distribution of components of the alloys. There are just some areas with reduced or increased TiC content, but they are not capable to alter the properties of the examined materials, Fig. 4 represents the microstructure of $50 \%$ vol. of TiC Co-based alloy with EDS scanning areas after heat resistance tests- the material beneath oxide film was analysed. Chemical composition of scanned areas is given in Tab. 3.

The darkest phase is titanium carbide with some minor content of the other alloying elements. Matrix material represents a mixture of cobalt (light phase) and chromium (grey phase) solid solutions. Light phase contains reduced (compared to nominal composition) amount of chromium, but increased amount of aluminium and iron. Lower chromium content in cobalt-based solid solution may become a reason for reduced heat resistance of the alloy.

Based on EDS analyses of Ni-40\% vol. TiC alloy after heat resistance testing, the chemical composition of the alloy was determined (Fig. 5). The results of the analyses are shown in Tab. 4.

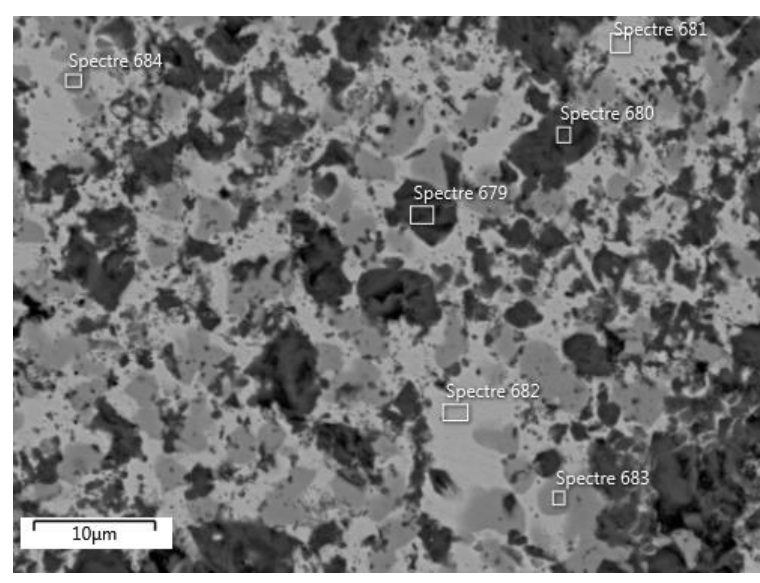

Fig. 4. Microstructure and distribution of chemical elements of cobaltbased alloy with $50 \%$ vol. of TiC after heat resistance test

Tab. 3. Chemical composition of scanned areas of cobalt alloy

\begin{tabular}{|c|c|c|c|c|c|c|}
\hline № & \multicolumn{5}{|c|}{ Composition, mass $\%$} & Note \\
\hline & Co & $\mathrm{Cr}$ & $\mathrm{Al}$ & $\mathrm{Fe}$ & $\mathrm{Ti}$ & \\
\hline 679 & 2.06 & 1.08 & 0.1 & 0 & 96.76 & \multirow{2}{*}{ (TiC) } \\
\hline 680 & 1.95 & 0.84 & 0 & 0.28 & 96.93 & \\
\hline 681 & 76.47 & 12.76 & 2.87 & 4.24 & 3.67 & \multirow{2}{*}{ Light phase } \\
\hline 682 & 78.32 & 12.9 & 2.87 & 4.17 & 1.74 & \\
\hline 683 & 12.93 & 81.41 & 0 & 1.14 & 4.52 & \multirow{2}{*}{ Grey phase } \\
\hline 684 & 23.11 & 73.33 & 0.23 & 1.92 & 1.41 & \\
\hline & 43.8 & 15.5 & 2.33 & 2.33 & $\begin{array}{c}33.8 \\
\mathrm{TiC}+\mathrm{TiH}\end{array}$ & $\begin{array}{c}\text { Nominal } \\
\text { composition }\end{array}$ \\
\hline
\end{tabular}

Three types of phases were clearly distinguished. The darkest phase - TiC grains, consisting of major amount of titanium with some admixtures of nickel and chromium. In contrast to cobaltbased alloys, aluminium and iron were not detected in the composition of titanium carbide, but it contains some amount of chromium and nickel. The grey phase was a nickel-based solid solution, containing significant, that is, more than 26 vol. $\%$ of chromium. Amount of the other alloying elements here was also higher 
if compared to nominal composition. This nickel solid solution with increased amount of alloying elements would probably have better heat resistance than cobalt solid solution. The light phase was a chromium based solid solution. Here, chromium segregation was more significant if compared to the cobalt-based alloy, and it contained fewer admixtures.

These results proved dissimilar diffusion rate of alloying elements in cobalt and nickel. For nickel, this process was much faster, which was indicated by the higher content of chromium, aluminium and iron. This provided a more dense oxide film with, particularly, high content of chromium.

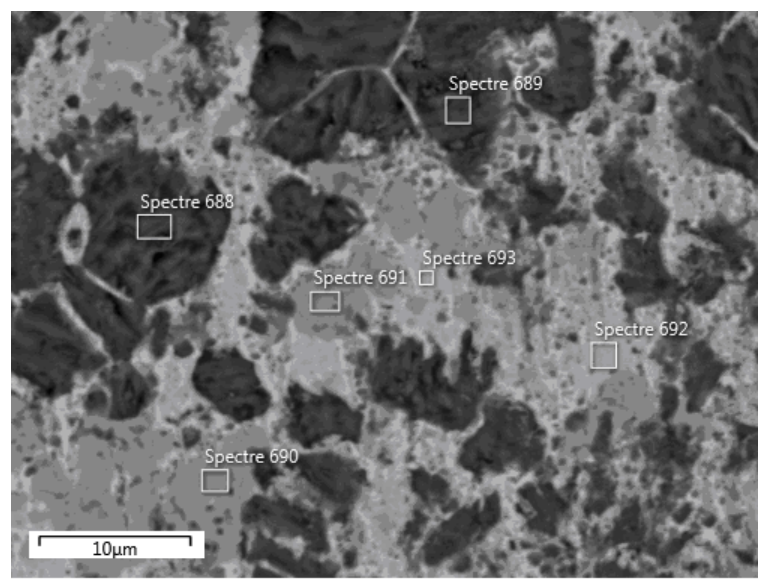

Fig. 5. Microstructure and distribution of chemical elements of $\mathrm{Ni}-40$ vol. \% TiC alloy after heat resistance test

Tab. 4. Chemical composition of scanned areas of nickel alloy

\begin{tabular}{|l|l|l|l|l|l|l|}
\hline № & \multicolumn{5}{|c|}{ Composition, mass \% } & Note \\
\hline & $\mathrm{Ni}$ & $\mathrm{Cr}$ & $\mathrm{Al}$ & $\mathrm{Fe}$ & $\mathrm{Ti}$ & \\
\cline { 1 - 6 } 688 & 0.5 & 0.22 & 0 & 0 & 99.28 & \multirow{2}{*}{ (TiC) } \\
\hline 689 & 0.87 & 0.52 & 0 & 0 & 98.61 & \\
\hline 690 & 2.13 & 92.77 & 0 & 1.39 & 3.71 & \multirow{2}{*}{ Light phase } \\
\hline 691 & 1.72 & 91.45 & 0 & 1.1 & 5.73 & \multirow{2}{*}{ Grey phase } \\
\hline 692 & 60.09 & 26.22 & 3.43 & 6.44 & 3.83 & $\begin{array}{c}\text { Nominal } \\
\text { composition }\end{array}$ \\
\hline
\end{tabular}

The light part of the micrograph was a nickel or cobalt based solid solution of alloying elements. Darker areas were particles of $\mathrm{TiC}$. The size of carbide particles was $5-10 \mu \mathrm{m}$, as initially it was in powders, so no TiC grain growth during prolonged heating at sintering was observed.

\subsection{Impact of porosity on heat resistance of $\mathrm{Ni}$ - and $\mathrm{Co}$-based powder alloys}

The analyses of heat resistance of the alloys have indicated that during the first 10 hours of test, high temperature oxidation runs quite fast; subsequently, it slows down and becomes almost constant. Heat resistance of alloys was dependent on heat resistance of both matrix and filler material. As far as heat resistance of $\mathrm{TiC}$ was less than heat resistance of cobalt and especially ZhS32-VI matrix, the increase of carbides content led to decrease of heat resistance. The other structural factor influencing heat resistance was porosity. The tests of heat resistance showed that increase of porosity led to decrease of heat resistance. The results of estimation of porosity impact on heat resistance of cobalt based alloys are presented on Fig. 6 and this is characteristic for all alloys despite matrix material and carbides content (Cherepova et al., 2015, Cherepova et al., 2016a). This is evident from Fig. 6 presenting weight increment at temperature $1100^{\circ} \mathrm{C}$ for alloys with identical content of $\mathrm{TiC}-50 \%$ vol. but dissimilar porosity.

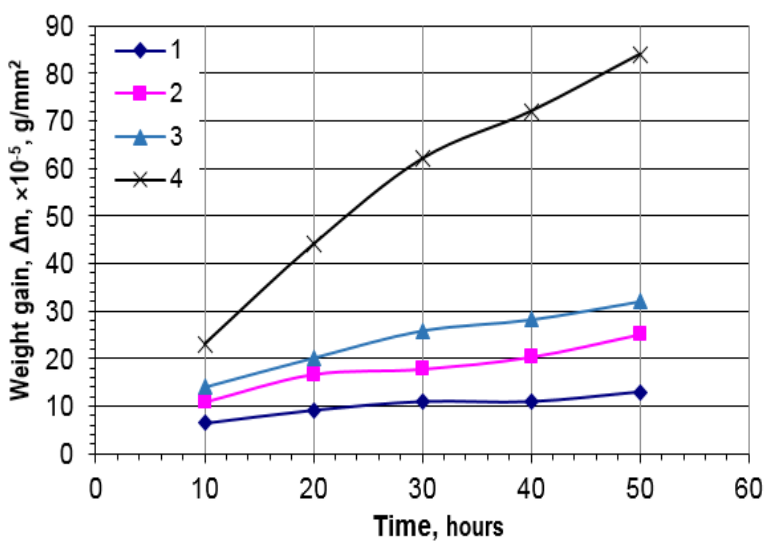

Fig. 6. Oxidation rate of cobalt-based alloys containing $50 \%$ vol. of TiC with dissimilar porosity: № $1-3.1 \%$; № $2-6.0 \%$; № $3-10.4 \%$; № $4-28.0 \%$

The rise of porosity from 3 to $28 \%$ caused an increase of weight gain in order of 3 after 10 hours of annealing. For alloys 1-3, further test gave likely steady weight gain, but for alloy № 4, it changed rapidly. After 50 hours of annealing, compared to alloy № 1, it had 6.5 times higher weight gain. Having this results, we supposed the existence of direst impact of porosity on heat resistance of Co-TiC alloys. The data from Fig. 6 allows to estimate the porosity impact on heat resistance as follows:

$I_{p}=\left(W g_{28}-W g_{3,1}\right) /(28-3.1)$

where $I_{p}$ is calculated value of porosity impact, $\mathrm{Wg}$ - weight gain for alloy with porosity marked in subscript. Increase of porosity caused proportional increase of weight gain - about $2.84 \times 10^{-5}$ $\mathrm{g} / \mathrm{mm}^{2}$ per $1 \%$ of porosity.

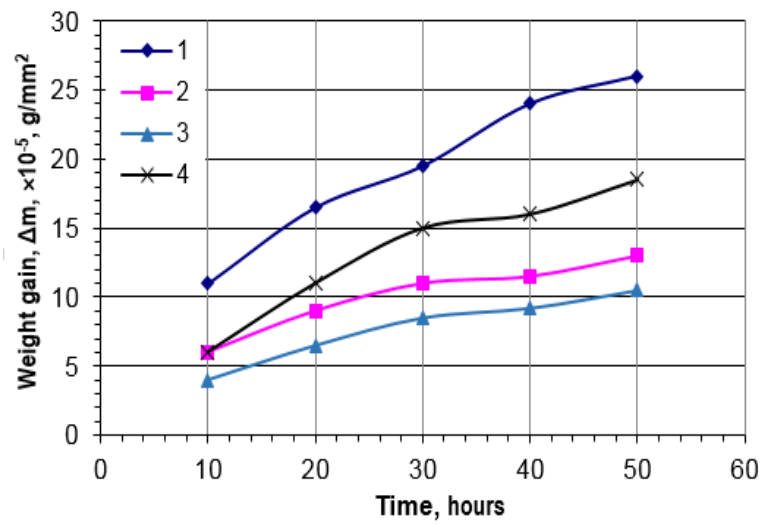

Fig. 7. Oxidation rate of nickel-based alloys containing $40 \%$ vol. of TiC with porosity: № 1 - 10\%; № $2-4.4 \%$; and $30 \%$ vol. of TiC with porosity: № 3 - 0\% (cast alloy); № $4-7.1 \%$ 
To evaluate the influence of porosity on oxidation of nickelbased alloys, four reference specimens were fabricated, containing 30 and 40 vol. \% of TiC, respectively. Their porosity ranged from $0 \%$ (cast alloy) up to $7.1 \%$. The results are presented in Fig. 7.

Here, the presence of porosity also causes increased weight gain. A cast alloy with 30 vol. \% of TiC and theoretical density has the highest heat resistance. The alloy having the same carbide content but $7.1 \%$ of porosity has 1.75 times higher weight gain. The calculated impact of porosity was $1.14 \times 10^{-5} \mathrm{~g} / \mathrm{mm}^{2}$ per $1 \%$ of porosity. The alloy containing $40 \mathrm{vol}$. $\%$ of TiC had the worst heat resistance. Increasing of porosity from 4.4 to $10 \%$ for this alloy caused increment of weight gain in 2 times and the calculated impact of porosity was $2.2 \times 10^{-5} \mathrm{~g} / \mathrm{mm}^{2}$ per $1 \%$

The presence of high number of pores facilitates oxygen supply into the material. The thickness of oxide layer in surface material may reach several tenth of micrometres. Porosity increases the surface area of material. Internal surfaces of pores are also subjected to oxidation. So, the interaction area increases, leading to higher oxidation rate of composite material. But, it should be mentioned that intrinsic heat resistance of matrix material (alloyed cobalt or nickel) and titanium carbide do not depend on porosity.

\subsection{Examination the composition of oxide films}

The results of EDS analyses of the edge of this alloy (Fig. 8) indicate the main elements taking part in oxidation. They are aluminium, chromium and cobalt (more intensive colour corresponds to higher content of chemical element). Fig. 8 gives the answer about the most active elements taking part in the formation of oxide film. They are, except the main matrix material, chromium and titanium. The oxides, formed by these elements are well known to be good barriers for further oxygen penetration into the material. Also, they are good to reduce the wear of examined materials in conditions of high temperature fretting wear.

As far as the content of aluminium in alloy is insignificant, it plays only auxiliary role in the oxidation process. Its amount in surface layer is not significant, but activated diffusion increases its quantity. Increased carbon content in surface layer is caused by oxidation and decomposition of TiC. Next analysed element is cobalt. Its content in surface layer seems to be unchanged, but results of previous analyses indicate areas (Fig. 4) with decreased or increased content of this element. Chromium content is sharply decreased in surface layer, but this is explained by significant oxygen uptake by oxide film, which is clearly observed on the corresponding diagram, Fig. 8. Also, partially it is substituted by aluminium. The change of iron distribution can hardly be detected on the diagram. Finally, the distribution of titanium corresponds to the microstructural distribution of TiC particles. Oxygen content is quite significant in surface layer. This is explained by the formation of protective oxide layer; it is mainly combined with cobalt, chromium and titanium.

The results of XRD analyses of oxide layer after the heat resistance test outline the primary chemical compounds formed during oxidation (Fig. 9-10).
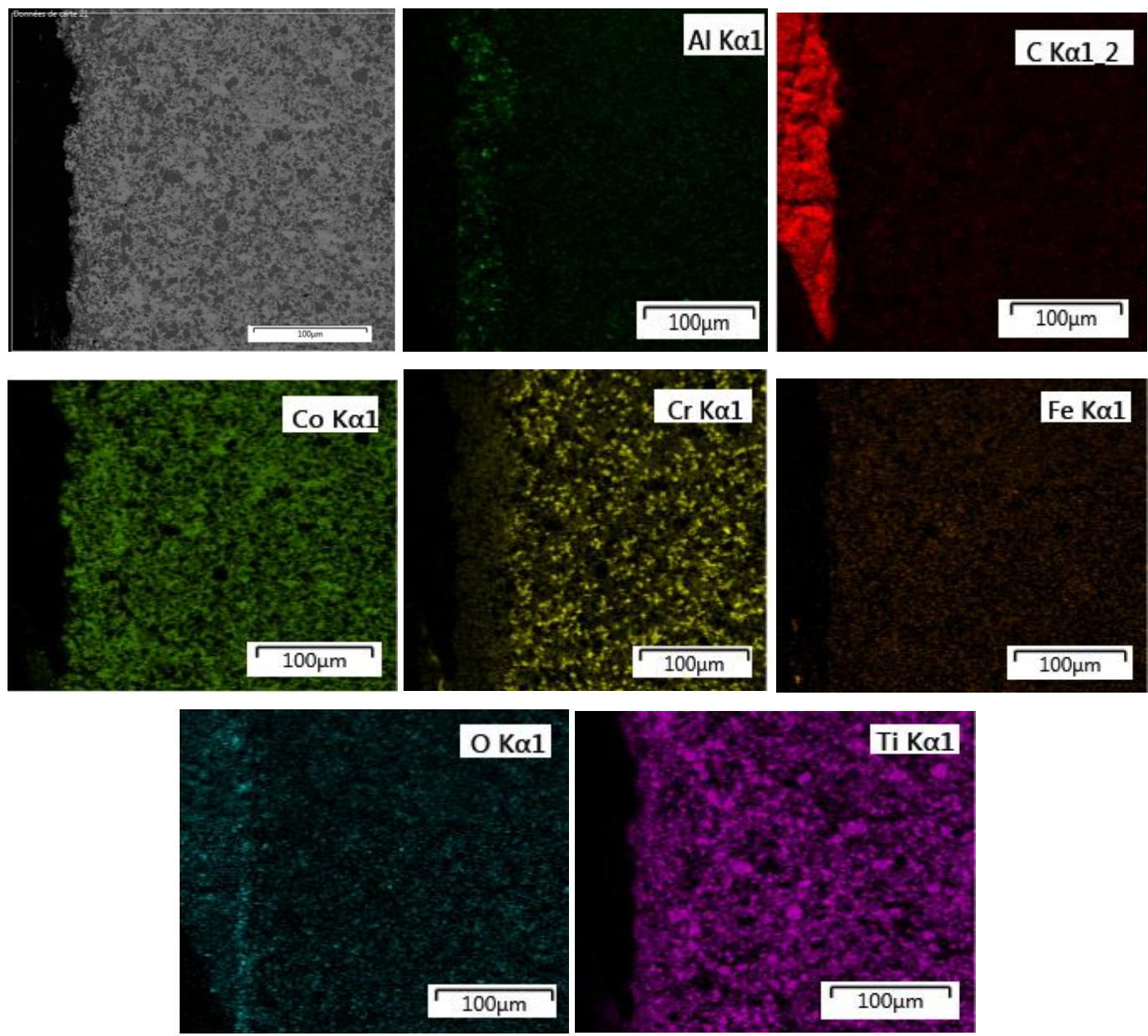

Fig. 8. EDS image and associated elemental map of the edge of the Co-50 vol. \% TiC composite alloy 


\section{sciendo}

Tetiana Cherepova, Galyna Dmitrieva, Oleksandr Tisov, Oleksandr Dukhota, Myroslav Kindrachuk Research on the Properties of Co-TiC and Ni-TiC HIP-Sintered Alloys

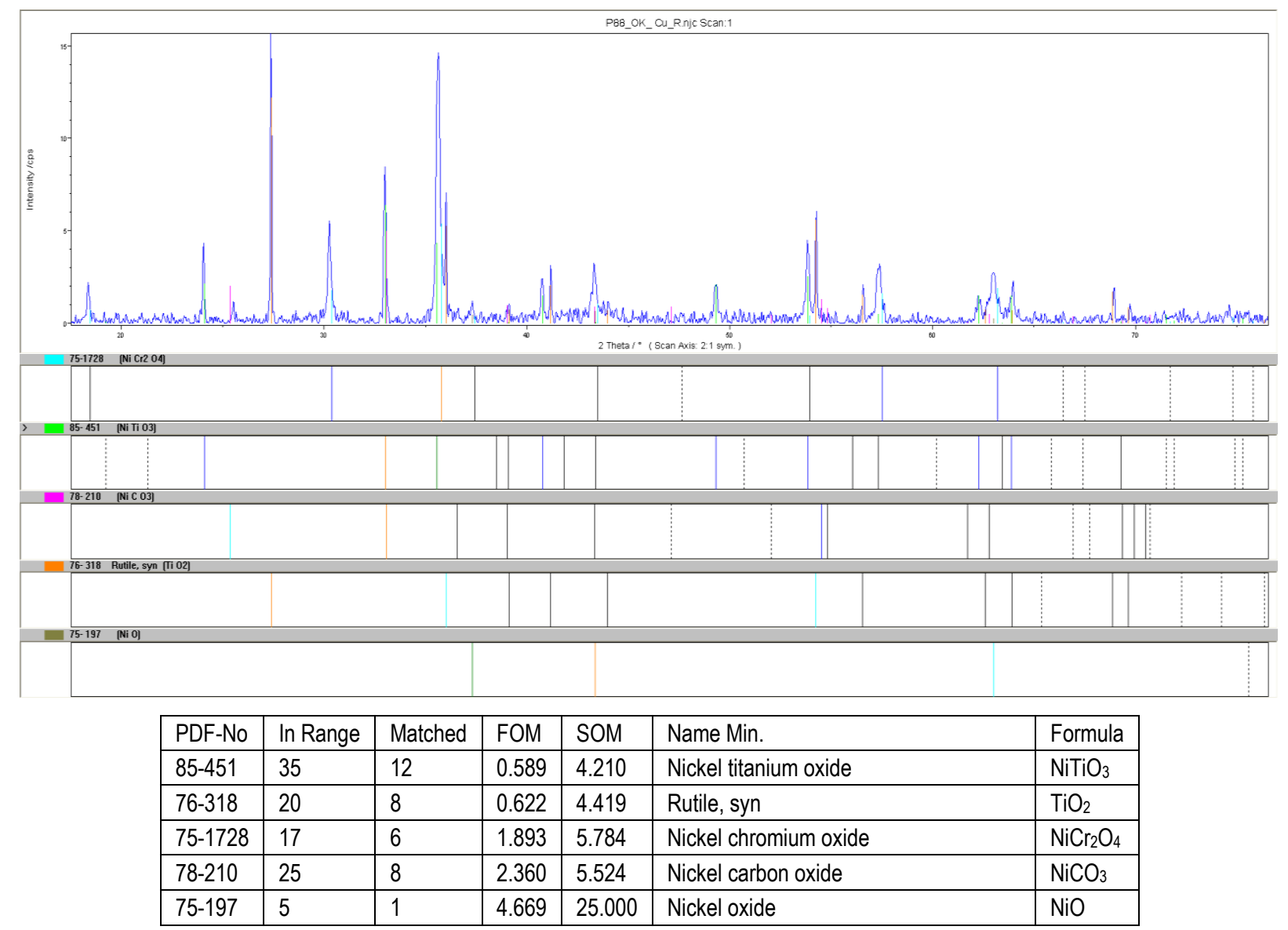

Fig. 9. XRD profile of scale powders of $\mathrm{Ni}+40 \%$ vol. TiC after heat resistance test $\left(1100^{\circ} \mathrm{C}\right)$

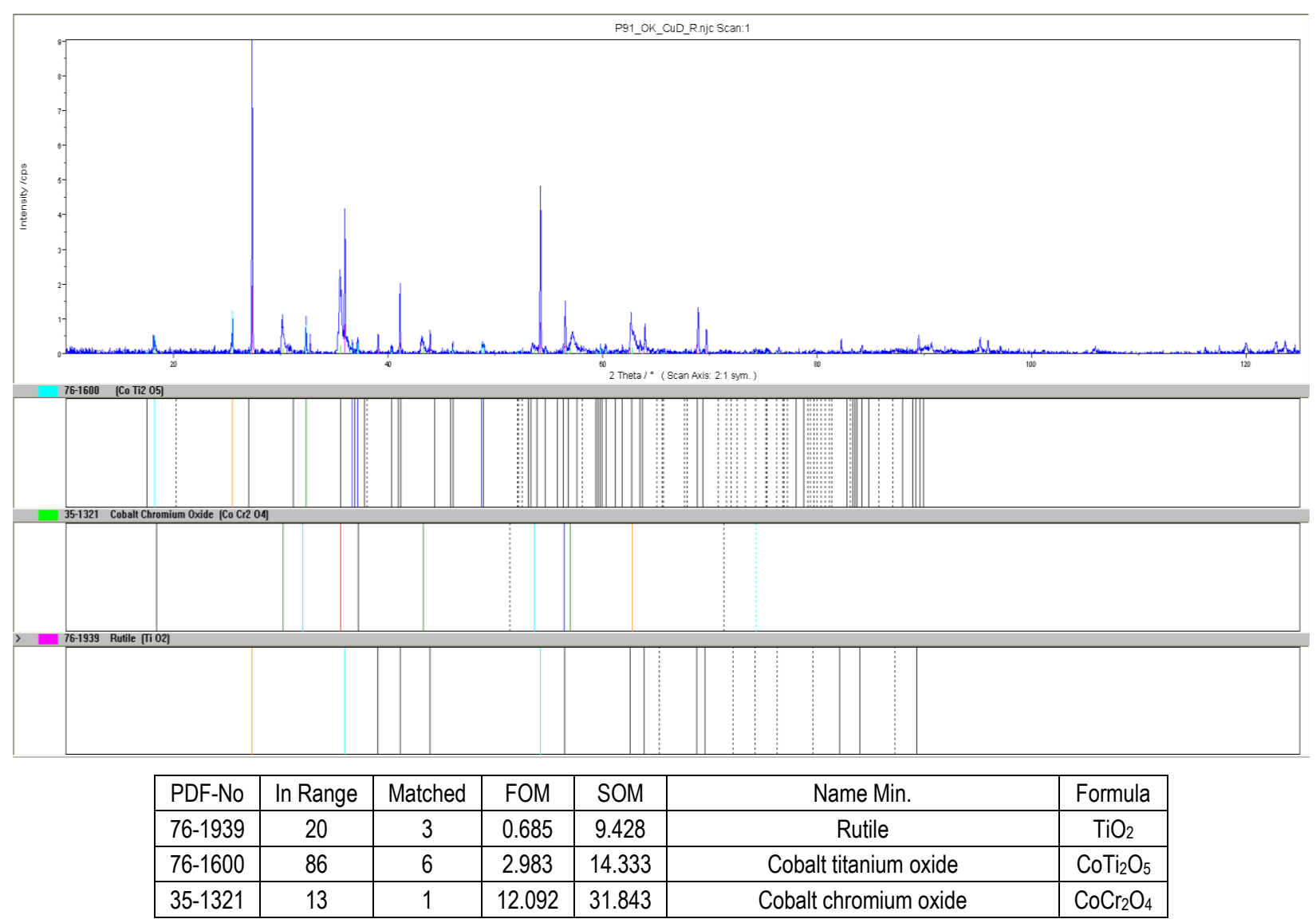

Fig. 10. XRD profile of scale powders of Co+50\% vol. TiC after heat resistance test $\left(1100^{\circ} \mathrm{C}\right)$ 
Based on the results of X-ray structural analyses, the basic components of scale on the surface of specimens ( $\mathrm{Ni}+40 \%$ vol. $\mathrm{TiC})$, after tests for heat resistance, were rutile $\mathrm{TiO}_{2}$, nickeltitanium oxide $\mathrm{NiTiO}_{3}$, nickel-chromium oxide $\mathrm{NiCr}_{2} \mathrm{O}_{4}$ and vustite $\mathrm{NiO}$. Fig. 9 presents the results of heat resistance testing of alloys containing $40 \%$ vol. of $\mathrm{TiC}$. Test temperature was $1100^{\circ} \mathrm{C}$. Here, the combination of oxides is more complex if compared to the cobalt-based alloy. Here, 5 chemical compounds were found, and the major was the quantity of nickel chromium oxide. The amount of titanium was much less than it was in previous case. It is interesting to mention the presence of unstable nickel carbonate Ni$\mathrm{CO}_{3}$. Usually, it decomposes into nickel and carbon oxides. It may appear temporally, as far as nickel oxide is found in significant quantities, and carbon oxide later evacuates from the oxide film.

Based on the results of X-ray structural analyses, the basic components of scale on the surface of specimens $(\mathrm{Co}+50 \%$ vol. $\mathrm{TiC}$ ), after tests for heat resistance, were ruthile (Fig 10), cobalttitanium oxide $\mathrm{CoTi}_{2} \mathrm{O}_{5}$ and cobalt-chromium oxide $\mathrm{CoCr}_{2} \mathrm{O}_{4}$. In other specimens of this type, the traces of ilmenite $\mathrm{FeTiO}_{3}$ were detected. The amount of titanium oxide was the highest among the formed chemical compounds. Cobalt titanium oxide followed it. This indicates that cobalt matrix does not provide a good protection of carbide grain. Chromium diffusion, as it was shown earlier in this paper, was not high enough to form a dense protective layer. The carbon content in oxide layer was not detected, while its content in sublayer (Fig. 8) was significant. It may be explained by higher reactivity of chromium to oxygen (carbides and carbooxides were not formed) and evaporation of carbon oxides out from the oxide layer. These factors provide lower heat resistance if compared with nickel-based alloy.

\subsection{Heat resistance test results}

The final test for heat resistance was done for sintered alloys containing the same amount of titanium oxide $-40 \mathrm{vol}$. $\%$ in order to find the best combination of matrix type. The results of these tests are presented on Fig. 11.

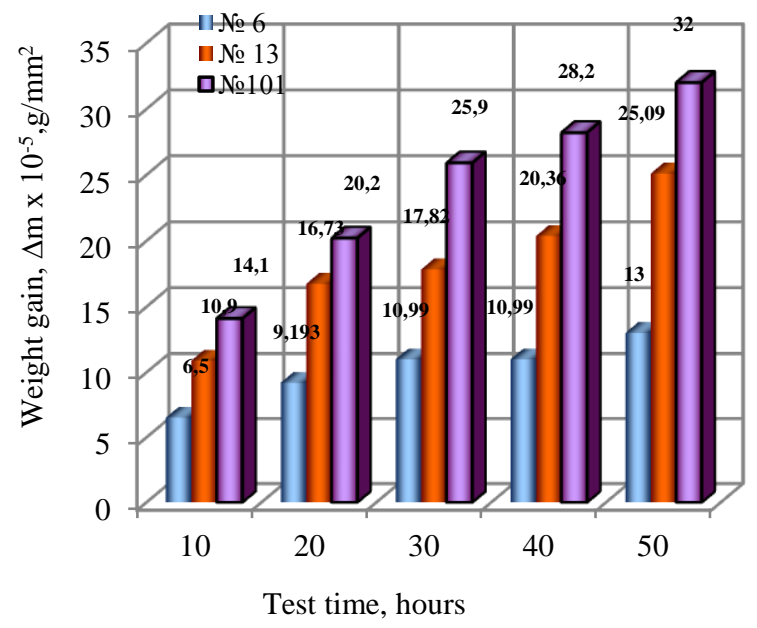

Fig. 11. Heat resistance of alloys with $40 \%$ vol. of TiC: № 6 - nickelbased; № 13 - cobalt-based; № 101 - based on ZhS32-VI

During all 50 hours of tests, the weight increment of nickelbased alloys remained the lowest. Of course, additional impact on heat resistance was provided by porosity. However, for the examined alloys, deviation was not significant and may be neglected. For all temperatures and stages of the test, heat resistance of nickel-based sintered alloy remained superior to others.

The oxidation of nickel and cobalt based alloys runs according to similar mechanism with formation of similar oxides (Fig. 9-10). They have the same amount and kind of alloying elements. Generally, they may be considered as $\mathrm{Ni}-\mathrm{Cr}$ and $\mathrm{Co}-\mathrm{Cr}$ systems. If chromium content is high enough, and a dense layer of $\mathrm{Cr}$ containing oxides are formed, the oxidation rate of alloys is almost the same, but oxidation resistance of cobalt is less than that of nickel. The adhesion of oxide layer to the substrate of nickelbased alloy is also higher (Dukhota and Tisov, 2010). These factors explain lower heat resistance of cobalt based alloys.

Alloy based on ZhS32-VI, which is used to produce turbine rotor blades, has the lowest heat resistance. This is explained by the purpose of the alloy. The main requirement to it is strength at high temperatures, but not high heat resistance. The surface of turbine blade is reliably protected by ambient barrier coatings. That is why heat resistance of sintered alloy based on ZhS32-VI is the lowest among the examined alloys, but it still has acceptable value.

\subsection{Wear resistance of examined alloys}

Wear resistance of alloys at high temperatures depend on heat resistance and high temperature strength. The results of fretting-wear test of cobalt-based (Cherepova and Dmytrieva, 2016a, 2016, Cherepova and Dmitrieva, 2016b), nickel-based (Cherepova et al, 2016) and alloys based on ZhS32-VI (Dmitrieva et al, 2017). These alloys were tested in a wide range of temperature and loads, in fretting-wear conditions (Dukhota et al, 2017). The summarized test result of alloys with titanium carbide $(50 \%$ vol.) as a strengthening phase are presented in Fig. 12. Maximum testing temperature was $1050^{\circ} \mathrm{C}$

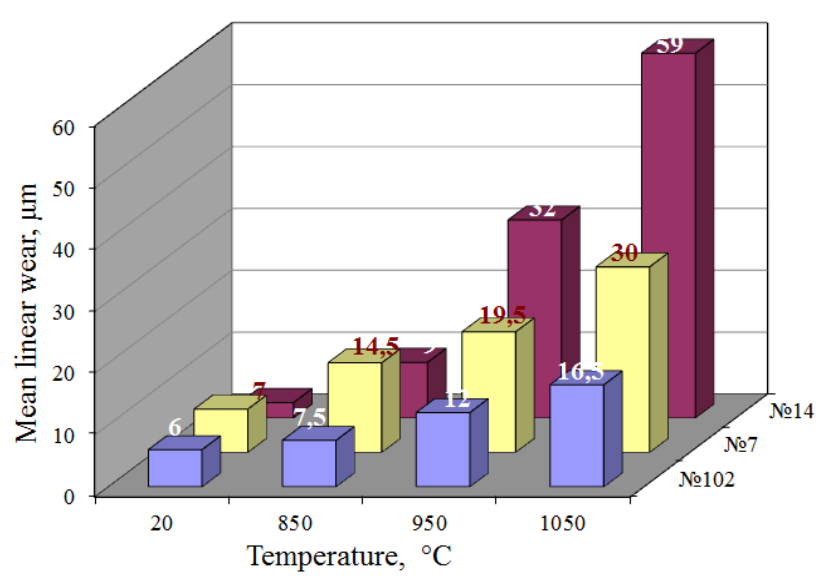

Fig. 12. Mean linear wear of sintered alloys with $50 \%$ vol. of TiC based on: №7 - nickel; №14 - cobalt; №102 - ZhS32-VI

Test results indicated superior fretting resistance of sintered alloy based on ZhS32-VI at all test temperatures. Most significantly, this was seen at temperature $1050^{\circ} \mathrm{C}$ - its linear wear was twice less than that of alloy based on nickel and almost three times less than that of alloy based on cobalt. This is explained by high strength of ZhS32-VI alloy, strengthened by precipitation of 
$\mathrm{Ni}_{3} \mathrm{Al}$ y' and by significant solution strengthening. Basically, it was stronger than nickel- and cobalt-based matrices.

At temperature range up to $\approx 900^{\circ} \mathrm{C}$, the nickel based alloys have twice as much value of wear as compared with cobalt-based alloys. However, at temperature of $1050^{\circ} \mathrm{C}$ cobalt-based alloys are twice as much superior than the nickel-based alloy. At lower temperatures, cobalt matrix is stronger, and for both alloys the oxidation is not significant. Predominant wear mechanism (based on earlier researches (Cherepova and Dmitrieva, 2016a, Cherepova et al., 2014, Dmitrieva et al., 2017) is abrasive wear. So, wear resistance is provided by strength and hardness of sintered alloys. At higher temperatures, oxidation wear is predominant and heat resistance and oxide layer adhesion to the substrate play an important role. As it was mentioned above, adhesion of nickel alloy oxide layer is stronger as compared with cobalt alloy.

Based on the conducted investigation, produced and examined alloys have good values of melting temperatures, wear resistance, heat resistance and technological properties and may be recommended for application as wear protective material for turbine rotor blades top shrouds. The availability of several materials with predictable wear resistance facilitates the choice of appropriate material for particular (stress and temperature) working conditions.

\section{CONCLUSIONS}

1. Three types of sintered alloys strengthened by TiC powders having alloyed cobalt, nickel or alloy ZhS32-VI matrices were produced. Results of DTA and SDC confirm that these alloys have no additional thermal effects and phase transitions until melting. Their melting temperatures are of the same order with industrial nickel-based alloys (basic materials for turbine blades manufacturing) and are in the range of $1320-1370^{\circ} \mathrm{C}$.

2. The tests for heat resistance indicated the highest properties of nickel-based alloy, followed by cobalt-based alloy and alloy with ZhS32-VI matrix. Heat resistance of sintered alloys is greatly affected by porosity: porosity increase from $3 \%$ up to $28 \%$ for $50 \%$ TiC cobalt based alloy weight gain rises in order of 8 . This is due to the facilitated oxygen inflow into the material, and high surface area of alloy, which includes the surface of pores. Increased porosity provides bigger specific area of the alloy, and therefore, the area, exposed to oxidation is much bigger then nominal surface area of test specimen. This results in increased weight gain during heat resistance test.

3. Based on the X-ray structural analyses, we revealed the formation of compound oxides $\mathrm{CoTi}_{2} \mathrm{O}_{5}$ and cobalt-chromium oxide $\mathrm{CoCr}_{2} \mathrm{O}_{4}$., ilmenite $\mathrm{FeTiO}_{3} \mathrm{TiO}_{2}$, nickel-titanium oxide $\mathrm{NiTiO}_{3}$, nickel-chromium oxide $\mathrm{NiCr}_{2} \mathrm{O}_{4}$ and vustite $\mathrm{NiO}$. On the wear surface, they formed 'glazed' ceramic-like layer protecting the material from further oxidation and improving its wear behaviour. This layer plays the role of a barrier, and oxygen diffusion into material is arrested. Also, being smooth, it reduces frictional losses. This layer is also better resistant to abrasive action of worn outcropped particles.

4. Wear tests in conditions of high temperature fretting indicate dissimilar wear resistance of materials. Cobalt alloys have the best wear resistance at room temperature. At higher temperature alloy based on ZhS32-VI matrix is superior as compared with others. Especially at temperature $1050^{\circ} \mathrm{C}$, it is two and three times more wear resistant as compared with $\mathrm{Ni}$ - and $\mathrm{Co}$ based alloys respectively.

5. Fabricated alloys have high enough melting point to undergo soldering and outgassing procedures entirely with turbine blade. Heat resistance of examined composites is superior or at least the same if compared with alloys (basically with ZhS32-Vl) used for manufacturing turbine blades. They also have good fretting resistance at high temperatures. Mentioned properties accompanied with structural stability and uniformity make these sintered composites promising to be used as wear protectives for contact faces of turbine blade top shrouds.

\section{REFERENCES}

1. Babak A., Barsoum M.W. (2016). Energy damping in magnesium alloy composites reinforced with TiC or Ti2AIC particles, Materials Science \& Engineering, A 653, 53-62.

2. Babak A., Casi E.N., Barsoum M.W. (2014), Fabrication and mechanical properties of pressureless melt infiltrated magnesium alloy composites reinforced with TiC and Ti2AIC particles, Materials Science and Engineering, 618, 511-522.

3. Baskaran S., Anandakrishnan V, Muthukannan Duraisel Vam, Keerthivasan N. (2015) Study on dry sliding friction behaviour of tic reinforced AA7075 in-situ composites by Taguchi analysis, International Journal of Mechanical And Production Engineering, 3(3), 9-12.

4. Bin C., Ye-fa T., Long H., Hua T., Li G. (2013), Tribological properties of TiC particles reinforced Ni-based alloy composite coatings, Transactions of Nonferrous Metals Society of China, 23(6), 1681-1688.

5. Cherepova T.S., Dmitrieva G.P. (2016a) The Wear Features of Powder Cobalt Alloys Strengthened with Titanium Carbide, Powder Metallurgy and Metal Ceramics, 55(5-6), 374-378.

6. Cherepova T.S., Dmitrieva G.P., Nosenko A.V., Semirga A.M. (2014) Wear-resistant alloy for protection of contact surfaces of working aircraft engine blades from oxidation at high temperatures, Science and Innovation, 10(4), 20-28.

7. Cherepova T.S., Dmytrieva H.P. (2016b) Properties of titanium carbide-strenghtened cobalt-based sintered alloys, Metal Physics and Advanced Technologies, 38(11), 1497-1512 (in Ukrainian).

8. Cherepova T.S., Dmytrieva H.P., Hosenko V.K. (2015) Heat resistance of cast and sintered alloys based on nickel and cobalt strengthened with carbides, Metallurgy and Heat Treatment of Metals, 3, 36-40 (in Ukrainian).

9. Cherepova, T.S., Dmitrieva, G.P., Nosenko, V.K. (2016a). Heat resistance of the powder cobalt alloys reinforced with niobium or titanium carbide, Science and Innovation, 12(1), 5-10.

10. Cherepova, T.S., Dmytrieva, H.P., Dukhota, O.I., Kindrachuk, M.V. (2016b) Properties of nickel powder alloys hardened with titanium carbide, Materials Science, 52(2), 173-179.

11. Chinmaya K.S., Manoj M. (2015). Effect of pulse laser parameters on TiC reinforced AISI 304 stainless steel composite coating by laser surface engineering process, Optics and Lasers in Engineering, $67,36-48$.

12. Chukwuma C., Onuoha X., Chenxin J., Zoheir N.F., Georges J.K., Kevin P.P. (2016). The effects of TiC grain size and steel binder content on the reciprocating wear behaviour of TiC-316L stainless steel cermets wear, Wear, 350-351, 116-129.

13. Dmitrieva G.P., Cherepova T.S., Kosorukova T.A., Nichiporenko V.I. (2015) Structure and properties of wear resistant cobalt-based alloy with niobium carbide, Metal Physics and Advanced Technologies, 37(7), 973-986 (in Russian).

14. Dmytrieva H.P., Cherepova T.S., Dukhota O.I., Nychyporenko V.I. (2017), Investigation of properties of sintered alloys based on ZhS32VI with titanium carbide, Powder Metallurgy, 11/12, 68-75 (in Ukrainian). 
15. Dukhota O.I., Tisov O.V. (2010), The study on wear resistance of heat resistant composite alloys in conditions of high temperature fretting-wear, Problems of friction and wear, 53, 195-200 (in Ukrainian).

16. Dukhota O.I., Tisov O.V., Cherepova T.S., Dmytrieva H.P., Kharchenko V.V. (2017), Tribotechnical examinations of high temperature wear resistant particle-reinforced alloys, Problems of friction and wear, 3(76), 60-66 (in Ukrainian).

17. Jung S.-A., Kwon H., Suh C.-Y., Oh J.-M., Kim W. (2015). Preparation of a fine-structured TiC-Co composite by high-energy milling and subsequent heat treatment of a Ti-Co alloy, Ceramics International, 41(10), 14326-14331.

18. Karantzalis A.E., Lekatou A., Evaggelidou M. (2013), Microstructure and sliding wear assessment of Co-TiC composite materials, International Journal of Cast Metals Research, 27(2), 73-79.

19. Levashov E.A., Mishina E.S., Malochkin O.V., Stanskii D.V., Mour J.J., Fadeev M. I. (2003). Effect of nanocrystalline powders on the structure and properties of dispersion-hardened alloy TiC - 40\% KhN70Yu, Metallurgist, 47(3/4), 133-139.

20. Lieontiev V.A., Zilichihis S.D., Kondratiuk Ye.V., Zamkovoi V.Ye. (2006). Recovery of workability of GTE using new technologies and materials, Herald of Engine Constructing, 4, 99-103 (in Russian).

21. Ouyang T., Wu J., Yasir M., Zhou T., Fang X., Wang Y., Liu D., Suo J. (2016), Effect of TiC self-healing coatings on the cyclic oxidation resistance and lifetime of thermal barrier coatings, Journal of Alloys and Compounds, 656, 992-1003

22. Sakamoto T., Kurishita H., Matsuo S., Arakawa H, Takahashi S, Tsuchida M., Kobayashi S., Nakai K,. Terasawa M., Yamasaki T., Kawai M. (2015) Development of nanostructured SUS316L-2\%TiC with superior tensile properties, Journal of Nuclear Materials, 466 468-476.

23. Shuster L.S., Mamleyev R.F., Kamaletdinova R.R., Chertovskikh S.V., Kireev R.M. (2016). Wear of friction pairs made of titanium carbide-based metal-ceramic material, Journal of Friction and Wear 37(2), 165-169.

24. Sun-A.J., Hanjung K., Chang-Yul S., Jung-Min O., Wonbaek K. (2015), Preparation of a fine-structured TiC-Co composite by high- energy milling and subsequent heat treatment of a Ti-Co alloy, Ceramics International, 41, 14326-14331.

25. Takahashi S., Ikeno S., Imai E. (1981). Differential thermal analysis and structure of the Ni-TiC system, Journal of Materials Science 16(12), 3418-3426.

26. Tretiachenko G.N., Kravchuk G.N., Kuriat R.I., Voloshchenko A.P. (1975) Bearing capacity of gas turbines blades at nonstationary haet and force effect, Kyiv.: Naukova Dumka (in Russian).

27. Volkova N. M., Dudorova T. A., Gurevich Y. G. (1989). Influence of hold time on carbide grain growth in TiC-Ni alloys, Soviet Powder Metallurgy and Metal Ceramics, 28(8), 613-617.

28. Wei Z.(2012). Research on Microstructure and Property of TiC-Co Composite Material Made by Laser Cladding, Physics Procedia, 25, 205-208.

29. Yuxin Li, Peikang Bai, Yaomin Wang, Jiandong Hu, Zuoxing Guo (2009). Effect of TiC content on Ni/TiC composites by direct laser fabrication, Materials \& Design, Vol. 30, Iss. 4. 1409-1412.

30. Zhang X.-H., Han J.-C., Du S.-Y., Wood J.V. (2000). Microstructure and mechanical properties of TiC-Ni functionally graded materials by simultaneous combustion synthesis and compaction, Journal of Materials Science, 35(8), 1925-1930.

31. Zohari S., Sadeghian Z., Lotfi B., Broeckmann C. (2015). Application of spark plasma sintering (SPS) for the fabrication of in situ $\mathrm{Ni}-$ TiC nanocomposite clad layer, Journal of Alloys and Compounds, $633,479-483$.

Acknowledgements: the present work is supported by funding from the Ministry of Education and Science of Ukraine, (Project \# 0117U004330 'Scientific fundamentals of designing novel technologies of surface engineering for elements of aircraft tribomechanical systems made of titanium alloys') and by the National Academy of Science of Ukraine (Project \# 0115 U003007 'Phase equilibria in multicomponent eutectic alloys based on $\mathrm{Al}, \mathrm{Co}, \mathrm{Ni}$ and $\mathrm{Ti}$, promising for use in power and civil engineering'). 